\title{
Upregulation of $\mathrm{CB}_{1}$ receptor binding in the ventromedial prefrontal cortex promotes proactive stress-coping strategies following chronic stress exposure
}

\author{
R.J. McLaughlin ${ }^{1,2}$, M.N. Hill ${ }^{3,4,5}$, S.S. Dang ${ }^{1}$, S.R. Wainwright ${ }^{1}$, L.A.M. Galea ${ }^{1}$, C.J. Hillard ${ }^{6}$, \\ and B.B. Gorzalka ${ }^{1}$ \\ ${ }^{1}$ Department of Psychology, University of British Columbia, 2136 West Mall, Vancouver, BC, \\ Canada, V6T 1 Z4 \\ ${ }^{2}$ Department of Psychiatry, McGill University, 1033 Pine Avenue West, Montreal, QC, Canada, \\ H3A 1 A 1 \\ ${ }^{3}$ Department of Cell Biology \& Anatomy, University of Calgary, Calgary, AB, Canada, T2N 4N1 \\ ${ }^{4}$ Department of Psychiatry, University of Calgary, Calgary, AB, Canada, T2N 4N1 \\ ${ }^{5}$ Department of The Hotchkiss Brain Institute, University of Calgary, Calgary, AB, Canada, T2N \\ $4 \mathrm{~N} 1$ \\ ${ }^{6}$ Department of Pharmacology \& Toxicology, Medical College of Wisconsin, 8701 Watertown \\ Plank Road, Milwaukee, WI, USA, 53226
}

\section{Abstract}

Accumulating evidence has revealed that dysregulation of the endocannabinoid system could contribute to the development of major depression. Studies carried out post-mortem in depressed suicide victims have revealed increased $\mathrm{CB}_{1}$ receptor binding site density in the prefrontal cortex (PFC). Accordingly, exposure of rodents to chronic unpredictable stress (CUS) results in phenotypic changes that mirror those of human depression, including increased $\mathrm{CB}_{1}$ receptor binding site density in the PFC. Our goal in these studies was to examine the effects of CUS on the density of $\mathrm{CB}_{1}$ receptor binding sites in the rodent medial PFC and to explore the role of this alteration in the behavioral changes invoked by CUS. Rodents exposed to CUS exhibited increased $\mathrm{CB}_{1}$ receptor maximal binding site density $\left(\mathrm{B}_{\max }\right)$ within the ventromedial $\mathrm{PFC}$, but not the dorsomedial PFC. To determine whether this change in the ventromedial PFC is an adaptive response, or alternatively, a consequence of chronic stress that contributes to the adoption of passive coping, we examined whether local $\mathrm{CB}_{1}$ receptor blockade within the ventromedial PFC following CUS would significantly alter behaviors in the forced swim test (FST). CUS exposure significantly increased passive coping in the FST, and this was further augmented by discrete ventromedial $\mathrm{PFC}$ microinfusions of the $\mathrm{CB}_{1}$ receptor antagonist AM251 prior to swim stress. Moreover, local $\mathrm{CB}_{1}$ receptor blockade reduced active coping responses in CUS-exposed rats. These findings suggest that the increase in $\mathrm{CB}_{1}$ receptor $\mathrm{B}_{\max }$ observed in the ventromedial PFC

\footnotetext{
(C) 2012 Elsevier B.V. All rights reserved.

Correspondence to be directed to: Ryan J. McLaughlin, PhD Department of Psychiatry McGill University 1033 Pine Avenue West Montreal, QC, Canada H3A 1A1 ryan.mclaughlin@ mcgill.ca Phone: 1-514-813-3248; Fax: 1-514-398-4866.

Publisher's Disclaimer: This is a PDF file of an unedited manuscript that has been accepted for publication. As a service to our customers we are providing this early version of the manuscript. The manuscript will undergo copyediting, typesetting, and review of the resulting proof before it is published in its final citable form. Please note that during the production process errors may be discovered which could affect the content, and all legal disclaimers that apply to the journal pertain.
} 
of rodents exposed to CUS maintains proactive coping strategies following chronic stress exposure.

\section{Keywords}

$\mathrm{CB}_{1}$ receptor; ventromedial prefrontal cortex; chronic unpredictable stress; forced swim test; microinfusion

The endocannabinoid system has recently emerged as a key component in the etiology of stress-related illnesses and could represent a novel therapeutic candidate for its treatment [1]. This system is comprised of a presynaptically located receptor $\left(\mathrm{CB}_{1}\right)$ and two endogenous ligands, $\mathrm{N}$-arachidonylethanolamine (AEA) and 2-arachidonoylglycerol (2AG), which are synthesized on-demand and serve to modulate excitatory, inhibitory, and monoaminergic neurotransmission in brain regions involved in the regulation of emotionality and stress [2,3]. Preclinical studies employing genetic deletion or chronic pharmacological antagonism of the $\mathrm{CB}_{1}$ receptor reveal a behavioral and neuroendocrine profile that resembles the phenotype of major depression in humans [4]. Likewise, rats exposed to chronic unpredictable stress (CUS), an animal model of depression [5,6], exhibit reduced $\mathrm{CB}_{1}$ receptor binding in subcortical limbic structures such as the hippocampus, hypothalamus, and ventral striatum [7-9].

While exposure to chronic stress and the development of a depressive phenotype are associated with reductions in endocannabinoid signaling in most brain regions, a different pattern has emerged in the prefrontal cortex (PFC). For example, CUS exposure induces a robust increase in $\mathrm{CB}_{1}$ receptor mRNA and binding in the PFC $[8,10,11]$. Furthermore, this increase in $\mathrm{CB}_{1}$ receptor binding in the $\mathrm{PFC}$ is normalized following chronic treatment with the monoamine uptake inhibitor imipramine [8] or URB597, an inhibitor of AEA degradation [11]. Similarly, increased $\mathrm{CB}_{1}$ receptor density and signaling in the PFC has been reported in another animal model of depression, olfactory bulbectomy (OBX) [12]. These changes were linked to alterations in anxiety-like behavior in the open field test; and both the increase in $\mathrm{CB}_{1}$ receptor density and increased anxiety behavior were reversed following chronic fluoxetine treatment [12].

Although these preclinical findings are intriguing, theses studies have only examined CUSor OBX-induced changes in $\mathrm{CB}_{1}$ receptor activity using whole PFC tissue samples. Thus, little is known regarding the precise anatomical subregion of the PFC affected by CUS exposure. Thus, we first sought to determine the effect of 21-day CUS exposure on $\mathrm{CB}_{1}$ receptor binding parameters specifically within the ventromedial PFC. This prefrontal subregion was chosen because of its structural and functional homology to the subcallosal cingulate gyrus (SCG) in humans, a cortical area that shows abnormal metabolic activity in major depression and is a target for deep brain stimulation in drug refractory depressives [13]. We also examined the dorsomedial PFC as a control region to determine the specificity of changes in the PFC evoked by CUS.

These preclinical data are in agreement with post-mortem reports from depressed suicide victims demonstrating that $\mathrm{CB}_{1}$ receptor protein expression, binding site density, and signal transduction are all increased in the PFC of these individuals [14-16]. Collectively, this suggests that increased $\mathrm{CB}_{1}$ receptor binding activity within the PFC is associated with the development of major depression. However, it is not currently known whether this increase in prefrontal $\mathrm{CB}_{1}$ receptor binding represents a compensatory adaptive response initiated to dampen the behavioral symptoms of depression induced by chronic stress, or alternatively, a driving factor that contributes to the development of these changes. Thus, the second goal of 
this study was to explore the contribution of CUS-induced alterations in $\mathrm{CB}_{1}$ receptor binding within the ventromedial PFC with respect to coping strategies in the forced swim test (FST).

Seventy-day-old male Sprague-Dawley rats (300 g; Charles River, Montreal, Canada) were housed in groups of three in standard maternity bins lined with contact bedding. Colony rooms were maintained at $21{ }^{\circ} \mathrm{C}$ on a 12-hr reverse light/dark cycle (lights off at $0700 \mathrm{hr}$ ). All rats were given ad libitum access to Purina Rat Chow and tap water. The guidelines of the Canadian Council on Animal Care were followed and the experiment was approved by the Animal Care Committee of the University of British Columbia.

Rats were randomly assigned to either CUS or control (CON) conditions prior to beginning the study. The CUS paradigm employed consists of 2-3 stressors per day for 21 days from the following list: $1 \mathrm{hr}$ tube restraint; $1 \mathrm{hr}$ exposure to social crowding with white noise/ stroboscopic illumination; $5 \mathrm{~min}$ forced swim exposure; $18 \mathrm{hr}$ food and/or water deprivation; $3 \mathrm{hr}$ cage rotation to alter dominance hierarchies; and $18 \mathrm{hr}$ social isolation in damp bedding. For studies where the FST was used as a behavioral endpoint, forced swim exposure in the CUS paradigm was replaced with $1 \mathrm{hr}$ cage tilt at a $30^{\circ}$ angle. All stressors were randomized and separated by a period of at least $2 \mathrm{hr}$. Rats assigned to the CON condition were handled three times per week for the duration of study.

On the morning after the final day of CUS, rats used for $\mathrm{CB}_{1}$ receptor binding analyses were decapitated and their brains were rapidly removed (n=6/group). The dorsomedial PFC (consisting of anterior cingulate and motor cortices) and ventromedial PFC (consisting of the prelimbic and infralimbic cortices) were dissected, flash-frozen in liquid nitrogen, and stored at $-80^{\circ} \mathrm{C}$ until analysis (see Fig. 1 for boundaries of dissection). $\mathrm{CB}_{1}$ receptor radioligand binding was performed using a Multiscreen Filtration System with Durapore $1.2-\mu \mathrm{M}$ filters (Millipore, Bedford, MA) as described previously [17]. Membranes (10 $\mu \mathrm{g}$ protein per incubate) were added to wells containing $0.1,0.25,0.5,1.0$ or $2.5 \mathrm{nM}$ of $\left[{ }^{3} \mathrm{H}\right]$ CP55940, a cannabinoid $\mathrm{CB}_{1}$ receptor agonist. Ten $\mu \mathrm{M} \Delta^{9}$-tetrahydrocannabinol was used to determine non-specific binding. The maximal $\mathrm{CB}_{1}$ receptor binding site density $\left(\mathrm{B}_{\max }\right)$ and affinity of $\left[{ }^{3} \mathrm{H}\right] \mathrm{CP} 55940$ for the $\mathrm{CB}_{1}$ receptor $\left(\mathrm{K}_{\mathrm{D}}\right)$ were determined by nonlinear curve fitting to the single site binding equation using GraphPad Prism (San Diego, CA, USA).

Independent t-tests conducted between control and CUS-exposed animals revealed that within the ventromedial $\mathrm{PFC}$, the maximal binding site density $\left(\mathrm{B}_{\max }\right)$ of the $\mathrm{CB}_{1}$ receptor was significantly greater in CUS-exposed animals $[t(9)=3.85, p<.005]$, with no significant differences in $\mathrm{K}_{\mathrm{D}}$. However, in the dorsomedial PFC, control and CUS-exposed animals did not differ significantly with respect to $\mathrm{B}_{\max }$ or $\mathrm{K}_{\mathrm{D}}$. These results suggest that the maximal binding site density of $\mathrm{CB}_{1}$ receptors is significantly higher within the ventromedial PFC of CUS-exposed animals (Fig. 2).

We hypothesized that the increase in ventromedial prefrontocortical $\mathrm{CB}_{1}$ receptor binding counteracts the effects of CUS for the following reasons. First, local activation of $\mathrm{CB}_{1}$ receptors or inhibition of AEA hydrolysis specifically within the ventromedial PFC has been shown to promote antidepressant-like responding in the FST $[18,19]$. Second, under neuropathological conditions, glial cells release an increased amount of endocannabinoids and over-express $\mathrm{CB}_{1}$ receptors in the PFC, which has been argued to constitute an endogenous defense mechanism that prevents additional cell damage [20]. In agreement with this notion, $\mathrm{CB}_{1}$ receptor knockout mice have been shown to exhibit dysregulation of the hypothalamic-pituitary-adrenal axis along with exacerbated excitotoxic/ neuroinflammatory responses in the PFC [21]. Given the negative impact of CUS exposure 
and the neuroprotective capacity of $\mathrm{CB}_{1}$ receptors in the $\mathrm{PFC}$, it is likely that the increase in $\mathrm{CB}_{1}$ receptor binding observed in the present study reflects a compensatory response.

To further examine the functional relevance of this change in $\mathrm{CB}_{1}$ receptor binding, separate cohorts of animals were randomly assigned to one of four groups (n=7/group): 1) CUSVEH; 2) CUS-AM251; 3) CON-VEH; 4) CON-AM251. These animals were implanted with bilateral cannula aimed at the ventromedial PFC prior to initiation of CUS, which occurred approximately 10-13 days post-surgery (see Fig. 1). Rats were anesthetized with a cocktail of $100 \mathrm{mg} / \mathrm{kg}$ of ketamine hydrochloride and $7 \mathrm{mg} / \mathrm{kg}$ xylazine and implanted with guide cannula using the coordinates $\mathrm{AP}=+3.0 ; \mathrm{ML}=+/-0.7 ; \mathrm{DV}=-3.4$, as described previously [22]. Following behavioral testing, tissue was sliced and stained with cresyl violet, and cannula placements were verified according to the stereotaxic atlas of Paxinos and Watson [23].

On the subsequent 2 days following CUS exposure, rats were tested in the FST during the middle third of the animals' dark cycle. Glass cylindrical containers (diameter $35 \mathrm{~cm}$, height $45 \mathrm{~cm}$ ) were filled with $30 \mathrm{~cm}$ of water maintained at $24 \pm 1^{\circ} \mathrm{C}$. Consistent with the modified method of testing in the FST, animals were subjected to two swim sessions [24]. The first swim session was a 15-min pre-exposure session, followed by a 5-min test session $24 \mathrm{hr}$ later. During the test session, the duration of immobility, swimming, and struggling was videotaped and scored by trained assistants blinded to experimental conditions (see [25] for a description of scoring criteria for each behavioral component).

Rats received intra-ventromedial PFC infusions of the $\mathrm{CB}_{1}$ receptor antagonist AM251 (Tocris Cookson Ltd., Bristol, UK) or vehicle 30 min prior to the day 2 swim session and were placed back into their home cages until testing began. AM251 (0.28 ng) or vehicle (1 part dimethyl sulfoxide, 9 parts $0.9 \%$ sterile saline) was administered at a volume of $0.2 \mu \mathrm{l} /$ side directly into the ventromedial PFC as described previously [22]. This dose was chosen in accordance with recent studies demonstrating behavioral and neuroendocrine effects following intracranial microinjection of AM251 at this dose [22,26].

A two-way ANOVA revealed a significant effect of interaction between stress and drug treatment on immobility in the FST $[F(1,24)=6.36, p<.02]$. Post-hoc analysis revealed that control animals receiving vehicle infusions (CON-VEH) spent significantly less time in an immobile posture compared to CUS-exposed rats receiving vehicle infusions (CUS-VEH; $p<.05$ ) and AM251 infusions (CUS-AM251; $p<.01$ ), but not relative to control rats receiving AM251 infusions (CON-AM251). Moreover, animals in the CUS-AM251 group showed significantly greater levels of immobility relative to those in the CUS-VEH group ( $p$ $<.05$; Fig. 3). A two-way ANOVA also revealed a significant effect of group on swimming behavior in the FST $[F(1,24)=3.84, p<.05]$. Follow-up analyses showed that although animals in the CON-VEH and CUS-VEH groups did not differ significantly, those in the CUS-AM251 group did demonstrate a significant reduction in swimming compared to those in the CUS-VEH $(p<.05)$, CON-VEH $(p<.05)$, and CON-AM251 $(p<.05)$ groups. There was no significant effect of group on struggling behavior (Fig. 3).

The results of this study support our hypothesis that increased ventromedial PFC CB 1 receptor density opposes the effects of CUS in the FST. Rats in both CUS-exposed groups (CUS-VEH and CUS-AM251) showed greater levels of immobility compared to control rats, which is reflective of enhanced passive stress coping strategies. Furthermore, rats in the CUS group pretreated with intra-ventromedial PFC infusions of the $\mathrm{CB}_{1}$ receptor antagonist AM251 prior to swim stress displayed the highest levels of immobility, even significantly more than those in the CUS group receiving vehicle infusions. Those in the CUS-AM251 treatment group also spent significantly less time swimming compared to those in all other 
treatment groups, which is suggestive of a reduced reliance on active, escape-directed coping strategies. Alterations in swimming behavior are thought to be mediated by changes in 5-HT transmission [24], and consistent with this, the antidepressant-like effect of intraventromedial $P F C C_{1}$ receptor activation occurs via interactions with this system $[18,19]$. Thus, it is possible that the increase in $\mathrm{CB}_{1}$ receptor binding observed in the present study may be acting to facilitate 5-HT output from midbrain monoaminergic nuclei. Together, these findings are consistent with our hypothesis that $\mathrm{CB}_{1}$ receptor activation in the ventromedial PFC promotes active coping in CUS-exposed rats. Moreover, these data suggest that CUS increases passive coping strategies via a mechanism that likely does not involve an increase in endocannabinoid signaling, but that increased endocannabinoid signaling can mitigate against the effects of CUS. Although this may be the most parsimonious explanation, it is also possible that local $\mathrm{CB}_{1}$ receptor antagonism exacerbated passive coping strategies in the FST by blocking stress-induced sensitization of a $\mathrm{CB}_{1}$ signaling pathway that occurs either independently from receptor binding changes, or through discrete receptor populations that do not show changes in binding characteristics.

The CUS-induced increase in $\mathrm{CB}_{1}$ receptor binding specifically within the ventromedial PFC is intriguing given that this region is a key determinant of depressive-like behavior and antidepressant responses both in clinical observations and preclinical studies. The rodent ventromedial PFC is functionally homologous to the SCG in humans [13,27], and notably, cellular and neuroimaging studies have revealed a reduction in immediate early gene expression and a substantial loss in gray matter in the SCG of depressed individuals [28,29]. Moreover, a variety of clinical interventions including pharmacological antidepressants, electroconvulsive shock treatment, and deep brain stimulation have all been associated with changes in activity in the SCG coinciding with symptom improvement [28]. Accordingly, stress-susceptible rodents exposed to chronic social defeat stress exhibit similar reductions in immediate early gene activity in the ventromedial PFC, while optogenetic stimulation of this population of neurons produces antidepressant-like effects in these animals [29]. Furthermore, deep brain stimulation of the rodent ventromedial PFC has also been shown to promote a robust increase in active coping responses in the FST that is dependent on the integrity of the serotonin (5-HT) system [30]. In agreement with this last report, local activation of $\mathrm{CB}_{1}$ receptors within the ventromedial PFC has been shown to elicit a similar 5-HT-mediated response in the FST [18]. Given that activation of $\mathrm{CB}_{1}$ receptors within the ventromedial PFC elicits active coping responses similar to optogenetic and deep brain stimulation, it is not surprising that local pharmacological $\mathrm{CB}_{1}$ receptor blockade further exacerbated passive coping behaviors (immobility) and reduced escape-directed behaviors (swimming) in the FST. These data are consistent with the fact that $\mathrm{CB}_{1}$ receptors in this region predominantly exist on GABAergic interneurons and the net effect of $\mathrm{CB}_{1}$ receptor activation in the medial PFC is an increase in the activation and outflow of projection neurons [22,31], similar to what would occur following focal stimulation of this region. It is also possible, however, that the CUS-induced increase in $\mathrm{CB}_{1}$ receptor binding is occurring primarily on astrocytes, where activation of $\mathrm{CB}_{1}$ receptor signaling can potentiate excitatory synaptic transmission [32]. Future work will be required to determine the neuronal or glial population mediating this effect.

The precise neurobiological mechanisms that are driving this change in $\mathrm{CB}_{1}$ binding are currently unknown. However, our laboratory has previously shown that a decrease in PFC AEA content also accompanies the increase in $\mathrm{CB}_{1}$ receptor binding [8], and pharmacological inhibition of FAAH during CUS exposure prevents the increase in $\mathrm{CB}_{1}$ receptor mRNA expression that occurs within the PFC [11]. Accordingly, exposure to chronic stress enhances FAAH activity in the medial PFC and amygdala [33], and moreover, this change in FAAH is necessary for the stress-induced changes in amygdalar structure and function [34]. Consequently, we speculate that the FAAH-mediated decrease in AEA 
content indirectly stimulates this compensatory up-regulation of $\mathrm{CB}_{1}$ receptor binding in the ventromedial $\mathrm{PFC}$ in an effort to maximize the diminishing AEA signaling pool induced by CUS exposure. Local pharmacological facilitation of $\mathrm{AEA} / \mathrm{CB}_{1}$ receptor signaling elicits antidepressant and anxiolytic responses in the FST and elevated plus maze, respectively $[19,35]$, so in this regard it is possible that this response is a mechanism engaged to curb changes in stress coping and anxiety induced by chronic stress. However, it should be noted that previous reports have failed to show enhanced FAAH activity following exposure to CUS $[8,11]$. Thus, it is possible that the increase in $\mathrm{CB}_{1}$ receptor binding could also be a result of diminished AEA biosynthesis, although this has yet to be empirically evaluated.

In conclusion, the findings from the present study support the notion that increased $\mathrm{CB}_{1}$ receptor binding in the ventromedial PFC facilitates proactive stress coping responses in response to CUS exposure. Future studies are needed to determine whether the local reduction in prefrontal AEA content is driving the increase in $\mathrm{CB}_{1}$ receptor binding, and whether pharmacologically maintaining AEA tone over the course of CUS exposure can prevent this increase in binding and produce a stress-resilient phenotype via interactions with the 5-HT system.

\section{Acknowledgments}

This work was supported by operating grants from the Canadian Institutes of Health Research (CIHR) to BBG, the National Institutes of Health (DA026996) to CJH, and the Natural Sciences and Engineering Research Council of Canada (NSERC) to BBG and LAMG. RJM is a recipient of a CIHR Canadian Graduate Student Doctoral Research Award. MNH is a recipient of a postdoctoral fellowship from CIHR. All authors report no biomedical financial interests or potential conflicts of interest.

\section{References}

1. Gorzalka BB, Hill MN. Putative role of endocannabinoid signaling in the etiology of depression and actions of antidepressants. Prog Neuropsychopharmacol Biol Psychiatry. 2011; 35:1575-85. [PubMed: 21111017]

2. Freund TF, Katona I, Piomelli D. Role of endogenous cannabinoids in synaptic signaling. Physiol Rev. 2003; 83:1017-66. [PubMed: 12843414]

3. McLaughlin RJ, Gobbi G. Cannabinoids and emotionality: a neuroanatomical perspective. Neuroscience. 2012; 204:134-44. [PubMed: 21827834]

4. Hill MN, Gorzalka BB. Is there a role for the endocannabinoid system in the etiology and treatment of melancholic depression? Behav Pharmacol. 2005; 16:333-52. [PubMed: 16148438]

5. Willner P. Chronic mild stress (CMS) revisited: consistency and behavioural-neurobiological concordance in the effects of CMS. Neuropsychobiology. 2005; 52:90-110. [PubMed: 16037678]

6. Hill MN, Hellemans KG, Verma P, Gorzalka BB, Weinberg J. Neurobiology of chronic mild stress: Parallels to major depression. Neurosci Biobehav Rev. 2012; 36:2085-117. [PubMed: 22776763]

7. Hill MN, Patel S, Carrier EJ, Rademacher DJ, Ormerod BK, Hillard CJ, et al. Downregulation of endocannabinoid signaling in the hippocampus following chronic unpredictable stress. Neuropsychopharmacology. 2005; 30:508-15. [PubMed: 15525997]

8. Hill MN, Carrier EJ, McLaughlin RJ, Morrish AC, Meier SE, Hillard CJ, et al. Regional alterations in the endocannabinoid system in an animal model of depression: effects of concurrent antidepressant treatment. J Neurochem. 2008; 106:2322-36. [PubMed: 18643796]

9. Reich CG, Taylor ME, McCarthy MM. Differential effects of chronic unpredictable stress on hippocampal CB1 receptors in male and female rats. Behav Brain Res. 2009; 203:264-9. [PubMed: 19460405]

10. Hillard CJ, Hill MN, Carrier EJ, Shi L, Cullinan WE, Gorzalka BB. Regulation of cannabinoid receptor expression by chronic unpredictable stress in rats and mice. Soc Neurosci Abstr. 2006:746.19. 
11. Bortolato M, Mangieri RA, Fu J, Kim JH, Arguello O, Duranti A, et al. Antidepressant-like activity of the fatty acid amide hydrolase inhibitor URB597 in a rat model of chronic mild stress. Biol Psychiatry. 2007; 62:1103-10. [PubMed: 17511970]

12. Rodriguez-Gaztelumendi A, Rojo ML, Pazos A, Diaz A. Altered CB receptor-signaling in prefrontal cortex from an animal model of depression is reversed by chronic fluoxetine. $\mathrm{J}$ Neurochem. 2009; 108:1423-33. [PubMed: 19183263]

13. Hamani C, Mayberg H, Stone S, Laxton A, Haber S, Lozano AM. The subcallosal cingulate gyrus in the context of major depression. 2011; 69:301-8.

14. Hungund BL, Vinod KY, Kassir SA, Basavarajappa BS, Yalamanchili R, Cooper TB, et al. Upregulation of CB1 receptors and agonist-stimulated [35S]GTPgammaS binding in the prefrontal cortex of depressed suicide victims. Mol Psychiatry. 2004; 9:184-90. [PubMed: 14966476]

15. Vinod KY, Arango V, Xie S, Kassir SA, Mann JJ, Cooper TB, et al. Elevated levels of endocannabinoids and CB1 receptor-mediated G-protein signaling in the prefrontal cortex of alcoholic suicide victims. Biol Psychiatry. 2005; 57:480-6. [PubMed: 15737662]

16. Choi K, Le T, McGuire J, Xing G, Zhang L, Li H, et al. Expression pattern of the cannabinoid receptor genes in the frontal cortex of mood disorder patients and mice selectively bred for high and low fear. J Psychiatr Res. 2012 [Epub ahead of print].

17. Hillard CJ, Edgemond WS, Campbell WB. Characterization of ligand binding to the cannabinoid receptor of rat brain membranes using a novel method: application to anandamide. J Neurochem. 1995; 64:677-83. [PubMed: 7830060]

18. Bambico FR, Katz N, Debonnel G, Gobbi G. Cannabinoids elicit antidepressant-like behavior and activate serotonergic neurons through the medial prefrontal cortex. J Neurosci. 2007; 27:1170011. [PubMed: 17959812]

19. McLaughlin RJ, Hill MN, Bambico FR, Stuhr KL, Gobbi G, Hillard CJ, et al. Prefrontal cortical anandamide signaling coordinates coping responses to stress through a serotonergic pathway. Eur Neuropsychopharmacol. 2012 [Epub ahead of print].

20. Massi P, Valenti M, Bolognini D, Parolaro D. Expression and function of the endocannabinoid system in glial cells. Curr Pharm Des. 2008; 14:2289-98. [PubMed: 18781979]

21. Zoppi S, Perez Nievas BG, Madrigal JL, Manzanares J, Leza JC, Garcia-Bueno B. Regulatory role of cannabinoid receptor 1 in stress-induced excitotoxicity and neuroinflammation. Neuropsychopharmacology. 2011; 36:805-18. [PubMed: 21150911]

22. Hill MN, McLaughlin RJ, Pan B, Fitzgerald M, Roberts CJ, Lee TT, et al. Recruitment of prefrontal cortical endocannabinoid signaling by glucocorticoids contributes to termination of the stress response. J Neurosci. 2011; 31:10506-15. [PubMed: 21775596]

23. Paxinos, G.; Watson, C. The rat brain in stereotaxic coordinates. 4th ed.. Academic Press; San Diego, CA: 1998.

24. Cryan JF, Valentino RJ, Lucki I. Assessing substrates underlying the behavioral effects of antidepressants using the modified rat forced swimming test. Neurosci Biobehav Rev. 2005; 29:547-69. [PubMed: 15893822]

25. McLaughlin RJ, Hill MN, Morrish AC, Gorzalka BB. Local enhancement of cannabinoid CB1 receptor signalling in the dorsal hippocampus elicits an antidepressant-like effect. Behav Pharmacol. 2007; 18:431-8. [PubMed: 17762511]

26. Campolongo P, Roozendaal B, Trezza V, Hauer D, Schelling G, McGaugh JL, et al. Endocannabinoids in the rat basolateral amygdala enhance memory consolidation and enable glucocorticoid modulation of memory. Proc Natl Acad Sci U S A. 2009; 106:4888-93. [PubMed: 19255436]

27. Ongur D, Ferry AT, Price JL. Architectonic subdivision of the human orbital and medial prefrontal cortex. J Comp Neurol. 2003; 460:425-49. [PubMed: 12692859]

28. Drevets WC, Price JL, Furey ML. Brain structural and functional abnormalities in mood disorders: implications for neurocircuitry models of depression. Brain Struct Funct. 2008; 213:93-118. [PubMed: 18704495]

29. Covington HE 3rd, Lobo MK, Maze I, Vialou V, Hyman JM, Zaman S, et al. Antidepressant effect of optogenetic stimulation of the medial prefrontal cortex. J Neurosci. 2010; 30:16082-90. [PubMed: 21123555] 
30. Hamani C, Diwan M, Macedo CE, Brandao ML, Shumake J, Gonzalez-Lima F, et al. Antidepressant-like effects of medial prefrontal cortex deep brain stimulation in rats. Biol Psychiatry. 2010; 67:117-24. [PubMed: 19819426]

31. Kiritoshi T, Sun H, Ren W, Stauffer SR, Lindsley CW, Conn PJ, et al. Modulation of pyramidal cell output in the medial prefrontal cortex by mGluR5 interacting with CB1. Neuropharmacology. 2012 [epub ahead of print] PMID: 22521499.

32. Navarrete M, Araque A. Endocannabinoid potentiate synaptic transmission through stimulation of astrocytes. Neuron. 2010; 68:113-126. [PubMed: 20920795]

33. Rademacher DJ, Meier SE, Shi L, Ho WS, Jarrahian A, Hillard CJ. Effects of acute and repeated restraint stress on endocannabinoid content in the amygdala, ventral striatum, and medial prefrontal cortex in mice. Neuropharmacology. 2008; 54:108-16. [PubMed: 17675104]

34. Hill MN, Kumar SA, Filipski SB, Iverson M, Stuhr KL, Keith JM, et al. Disruption of fatty acid amide hydrolase activity prevents the effects of chronic stress on anxiety and amygdalar microstructure. Mol Psychiatry. 2012 [epub ahead of print] doi: 10.1038/mp.2012.90.

35. Rubino T, Realini N, Castiglioni C, Guidali C, Vigano D, Marras E, et al. Role in anxiety behavior of the endocannabinoid system in the prefrontal cortex. Cereb Cortex. 2008; 18:1292-1301. [PubMed: 17921459] 


\section{Highlights}

- CUS exposure increased $\mathrm{CB}_{1}$ receptor binding sites in the rat ventromedial PFC

- Local ventromedial PFC $\mathrm{CB}_{1}$ blockade exacerbated CUS-induced immobility in the FST

- Ventromedial PFC $\mathrm{CB}_{1}$ blockade also decreased active coping in the FST following CUS

- CUS-induced upregulation of ventromedial $\mathrm{PFC} \mathrm{CB}_{1}$ binding serves an adaptive purpose 
A.

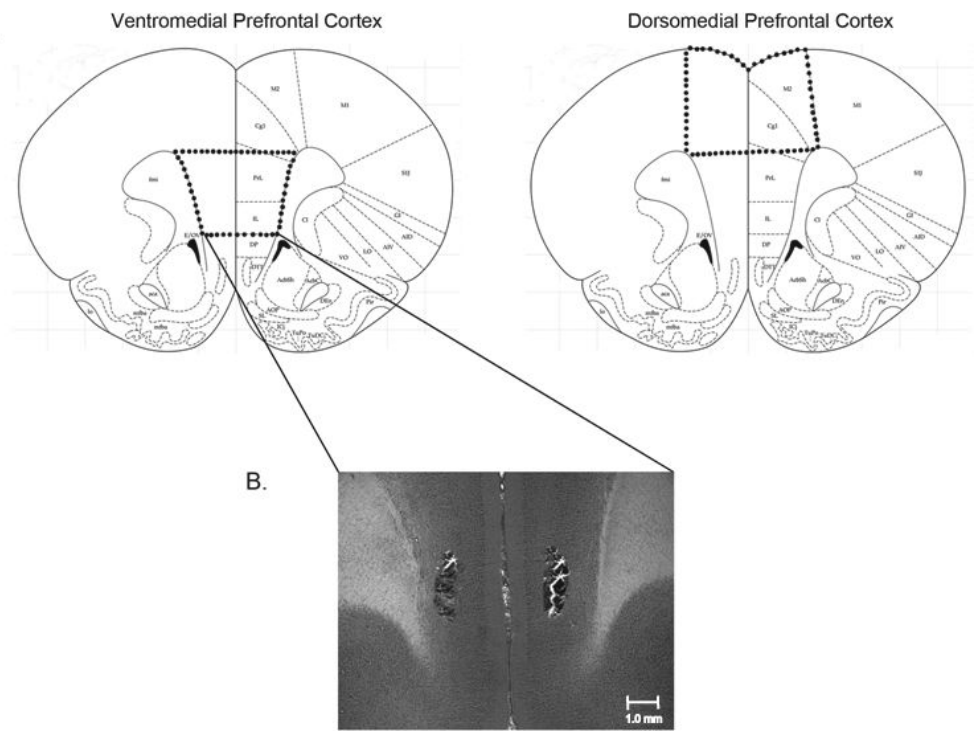

Figure 1.

Diagram depicting the boundaries for dissection for dorsomedial and ventromedial prefrontal cortex tissue extractions (above). Representative photomicrograph showing a bilateral cannula placement for rats receiving microinfusions into the ventromedial prefrontal cortex (below). 

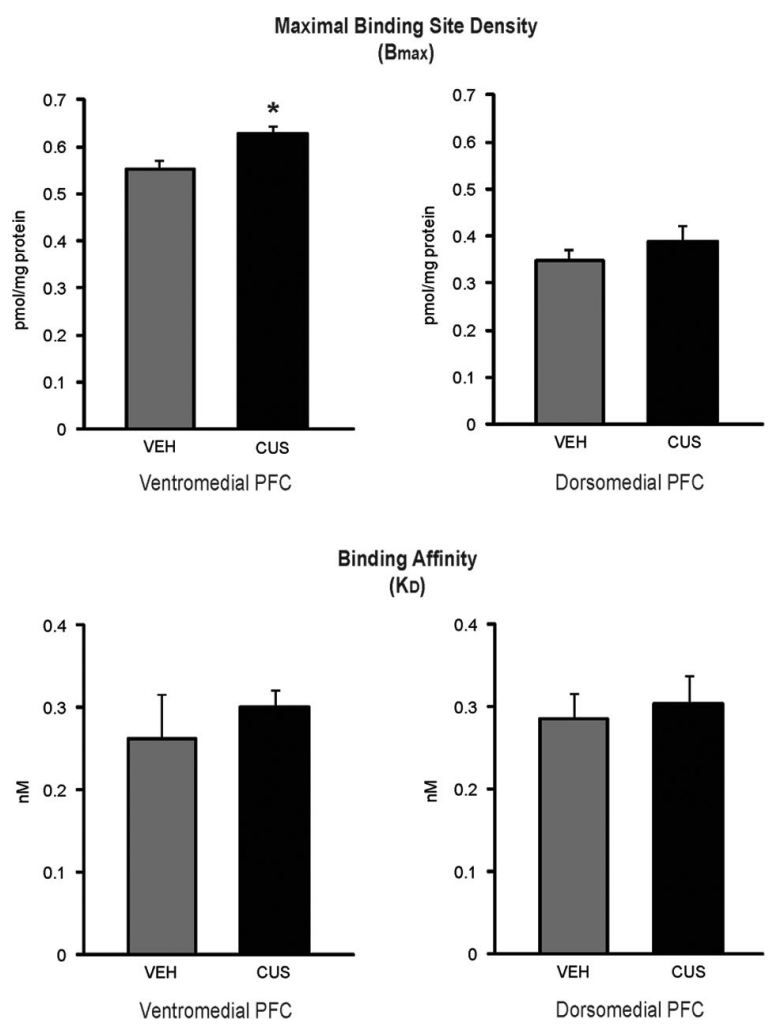

Figure 2.

The effect of chronic unpredictable stress (CUS) on the maximal binding site density ( $\mathrm{B}_{\max }$ in $\mathrm{pmol} / \mathrm{mg}$ protein) and binding affinity $\left(\mathrm{K}_{\mathrm{D}}\right.$ in $\left.\mathrm{nM}\right)$ of $\mathrm{CB}_{1}$ receptors in the dorsomedial and ventromedial prefrontal cortex $(\mathrm{n}=6 /$ group$) . *$ denotes $\mathrm{p}<.05$. 


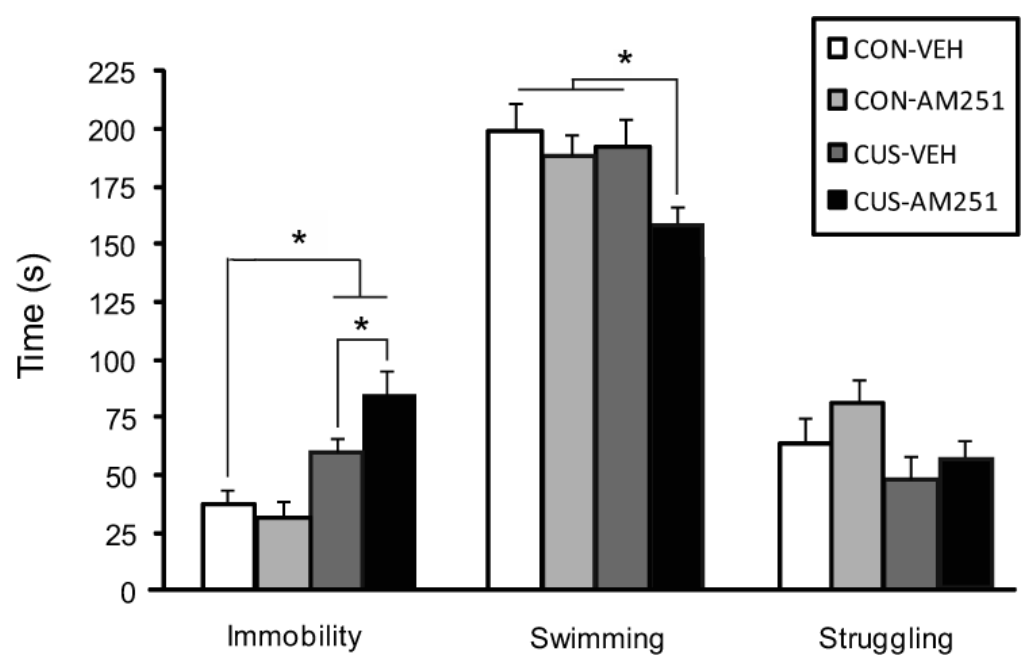

Figure 3.

The effect of local ventromedial PFC administration of the $\mathrm{CB}_{1}$ receptor antagonist AM251 $(0.28 \mathrm{ng})$ on immobility, swimming, and struggling behaviors in the forced swim test in control and CUS-exposed animals ( $\mathrm{n}=7$ /group). ${ }^{*}$ denotes $\mathrm{p}<.05$. 